Pacific Journal of Mathematics

THE GENERALIZED GIBBS PHENOMENON FOR REGULAR 


\title{
THE GENERALIZED GIBBS PHENOMENON FOR REGULAR HAUSDORFF MEANS
}

\author{
Jonah Mann and Donald J. Newman
}

One says that the means $\sigma_{n}(x)$, of the Fourier series of a function $f(x)$, exhibit the (generalized) Gibbs phenomenon at the point $x=x_{0}$ if the interval between the upper and lower limit of $\sigma_{n}(x)$, as $n \rightarrow \infty$ and $x \rightarrow x_{0}$ independently, contains points outside the interval between the upper and lower limits of $f(x)$ as $x \rightarrow x_{0}$. Theorem. In order that the Hausdorff summability method given by $g(t)$ not display the Gibbs phenomenon for any Lebesgue integrable function, it is necessary and sufficient that $1-g(t)$ be positive definite. A new inequality which must be satisfied by $g(t)$, whenever $1-g(t)$ is positive definite, is $\operatorname{Re} z \int_{0}^{1}(1-z t)^{n} d g(t) \geqq 0$ where $z=1-e^{i x}$.

This generalized definition of Gibbs phenomenon is an extension of the classical one, and is due to Kuttner [4].

Whereas originally the phenomenon was investigated for functions having a simple discontinuity at the point considered, he includes any Lebesgue integrable function. Kuttner proved the following:

THEOREM. In order that a given $K$-method [3, P. 56] not display the Gibbs phenomenon for any Lebesgue integrable function, it is necessary and sufficient that the kernel $K_{n}(x)$ be bounded below.

Here $K_{n}(x)$ are the means of the series $1 / 2+\cos x+\cos 2 x+\cdots$. For regular Hausdorff means [10] (which, being triangular, are $K$-methods) the kernel takes the form

$$
K_{n}(x)=\operatorname{Im} \frac{e^{i x / 2}}{2 \sin x / 2} \int_{0}^{1}\left(1-t+t e^{i x}\right)^{n} d g(t)
$$

where $g(t)$ is of bounded variation in $0 \leq t \leqq 1, g(0+)=g(0)=0$, and $g(1)=1$. We find it useful to let $g(t)$ be normalized in $0 \leq t \leq 1$, and to define it outside this interval by $g(t)=1$ for $t>1$ and $g(-t)=g(t)$.

THEOREM. In order that the Hausdorff summability method given by $g(t)$ not display the Gibbs phenomenon for any Lebesgue integrable function, it is necessary and sufficient that $1-g(t)$ be positive definite.

Received February 24, 1964. 
(For the status of the corresponding problem for the classical Gibbs phenomenon, see [8], [7], and [6].)

Proof of necessity. We shall show that $K_{n}(x)$ is not bounded below if $1-g(t)$ is not positive definite. Since $\left|1-t+t e^{i x}\right| \leqq 1$, Im $i \int_{0}^{1}\left(1-t+t e^{i x}\right)^{n} d g(t)$ is bounded, and it suffices to consider

$$
h_{n}(x)=\operatorname{Im} \cot x / 2 \int_{0}^{1}\left(1-t+t e^{i x}\right)^{n} d g(t) .
$$

Let $1-t+t e^{i x}=R e^{i \alpha}$. Therefore $R \cos \alpha=1-t+t \cos x, R \sin \alpha=$ $t \sin x, R^{2}=1-2 t(1-t)(1-\cos x)$, and

$$
\tan (x / 2) h_{n}(x)=\operatorname{Im} \int_{0}^{1} R^{n} e^{i n \alpha} d g(t)=\int_{0}^{1} R^{n} \sin n \alpha d g(t) .
$$

We now choose a sequence of $n$ and $x$ so that $n x \rightarrow A<\infty, A$ to be specified later, as $n \rightarrow \infty$ and $x \rightarrow 0$. Szász [8] shows that $1-R^{n}=\lambda n\left(1-R^{2}\right)$ where $0<\lambda<1$, and

$$
\sin n \alpha-\sin n t x=2 \cos n(\alpha+t x) / 2 \cdot \sin 0\left(n t x^{3}\right) .
$$

Since $1-R^{2}<x^{2}$ and $n x \rightarrow A$, it follows that

$$
\begin{aligned}
\tan (x / 2) \cdot h_{n}(x) & =\int_{0}^{1} \sin n t x d g(t)+0(x) \\
& =n x \int_{0}^{1} \cos n t x \cdot(1-g(t)) d t+0(x) .
\end{aligned}
$$

The last equality is obtained by integrating by parts.

According to the way the definition of $g(t)$ was extended,

$$
\tan (x / 2) \cdot h_{n}(x)=(n x / 2) \int_{-\infty}^{\infty} e^{i n x t}(1-g(t)) d t+0(x) .
$$

Since $1-g(t)$ belongs to $L^{1}(-\infty, \infty)$ and is of bounded variation in $(-\infty, \infty)$, it follows from Bochner's theorem [2] that its Fourier transform is not always nonnegative. Consequently, there is an $A_{o}>0$ for which

$$
\int_{-\infty}^{\infty} e^{i A_{0} t}(1-g(t)) d t=-B<0 .
$$

Then let $A=A_{o}$ and obtain $\tan (x / 2) \cdot h_{n}(x) \rightarrow-A_{o} B / 2$. (Taking the limit under the integral sign is permitted by "bounded convergence".) This implies that $h_{n}(x) \rightarrow-\infty$, and completes this part of the proof.

Proof of sufficiency. We shall show now that $K_{n}(x)$ is not only bounded below when $1-g(t)$ is positive definite but is, in fact, positive for all $n$ and $x$. 


$$
K_{n}(x)=\operatorname{Im} \frac{e^{i x / 2}}{2 \sin x / 2} \int_{0}^{1}\left[1-\left(1-e^{i x}\right) t\right]^{n} d g(t) .
$$

Let $z=1-e^{i x}$. Then

$$
\begin{aligned}
K_{n}(x) & =\operatorname{Im} \frac{i z}{4 \sin ^{2} x / 2} \int_{0}^{1}(1-z t)^{n} d g(t) \\
& =\operatorname{Re} \frac{z}{4 \sin ^{2} x / 2} \int_{0}^{1}(1-z t)^{n} d g(t) .
\end{aligned}
$$

Let $f_{n}(t)=(1-z t)^{n+1}$ in $0 \leq t \leq 1$ and $(1+\bar{z} t)^{n+1}$ in $-1 \leqq t<0$. Therefore

$$
K_{n}(x)=\frac{-1}{8(n+1) \sin ^{2} x / 2} \int_{-1}^{1} f_{n}^{\prime}(t) d g(t) .
$$

It suffices to show that

$$
\int_{-1}^{1} f_{n}^{\prime}(t) d g(t) \leq 0
$$

Let $G(t)=f_{o}(t) e^{-i x t}$. Since $G(-t)=G(1-t)$ for $0 \leqq t \leqq 1, f_{o}(t)$ may be defined for $t,|t|>1$, so that $G(t)$ will be periodic of period 1 .

Now

$$
\begin{aligned}
\int_{-1}^{1} G(t) e^{-2 \pi i k t} d t & =2 \int_{0}^{1}\left[1-\left(1-e^{i x}\right) t\right] e^{-i x t} e^{-2 \pi i k t} d t \\
& =\frac{4(1-\cos x)}{(x+2 \pi k)^{2}} .
\end{aligned}
$$

Consequently

$$
G(t)=\sum_{k=-\infty}^{\infty} C_{k} e^{2 \pi i k t} \text { where each } C_{k} \geqq 0 .
$$

$G(t)$, therefore, is positive definite, and since the product of two positive definite functions is positive definite, it follows that $f_{o}(t)$ is positive definite. Also, each $f_{n}(t)$ is positive definite if it is defined for $t,|t|>1$, by

$$
f_{n}(t)=e^{i(n+1) x t}[G(t)]^{n+1}
$$

Therefore

$$
f_{n}(t)=a_{0}+\sum_{k=1}^{\infty}\left(a_{k} \cos \lambda_{k} t+i b_{k} \sin \lambda_{k} t\right)
$$

where $a_{k} \geqq 0$ and $\lambda_{k}>0, k=1,2, \cdots$, and

$$
f_{n}^{\prime}(t)=\sum_{k=1}^{\infty}\left(-a_{k} \lambda_{k} \sin \lambda_{k} t+i b_{k} \lambda_{k} \cos \lambda_{k} t\right)
$$

so that 


$$
\int_{-1}^{1} f_{n}^{\prime}(t) d g(t)=\sum_{k=1}^{\infty} \int_{-1}^{1}\left(-a_{k} \lambda_{k} \sin \lambda_{k} t+i b_{k} \lambda_{k} \cos \lambda_{k} t\right) d g(t)
$$

Since $f_{n}^{\prime}(t)$ is of bounded variation, its Fourier series is boundedly convergent [9, P. 408] and the order of summation and integration may be interchanged $[1, \mathrm{P} .74]$.

$$
\begin{aligned}
\int_{-1}^{1} \cos A t d g(t) & =0 \text { since } g(t) \text { is even, and } \\
\int_{-1}^{1} \sin A t d g(t) & =A \int_{-1}^{1} \cos A t(1-g(t)) d t \\
& =A \int_{-\infty}^{\infty} e^{i \Delta t}(1-g(t)) d t
\end{aligned}
$$

which is positive for positive $A[2, \mathrm{P} .26]$ since $1-g(t)$ is positive definite and belongs to $L^{1}(-\infty, \infty)$. Finally

$$
\int_{-1}^{1} f_{n}^{\prime}(t) d g(t) \leq 0
$$

and the theorem is proved.

This result, about positive kernels, may be compared with Kuttner's result in [5].

It is worth noting that we have proved

$$
\operatorname{Re} z \int_{0}^{1}(1-z t)^{n} d g(t) \geqq 0,
$$

where $z=1-e^{i x}$, whenever $1-g(t)$ is positive definite. This provides some new inequalities which must be satisfied by a class of positive definite functions which is encountered quite often. For example, when $n=1$ and $x=\pi$, we obtain

$$
\int_{0}^{1}(1-2 t) d g(t) \geq 0 \text {. }
$$

\section{REFERENCES}

1. J. C. Burkill, The Lebesgue integral, Camb. Tracts in Math. and Math. Phys. no. 40, Cambridge, 1958.

2. R. R. Goldberg, Fourier transforms, Cambridge, 1961.

3. G. H. Hardy and W. W. Rogosinski, Fourier series, 2nd ed., Cambridge Tracts no. 38, Cambridge, 1962.

4. B. Kuttner, Note on the Gibbs phenomenon, J. London Math. Soc. 20 (1945), 136-139.

5. - A further note on the Gibbs phenomenon, J. London Math. Soc. 22 (1947), 295-298.

6. J. Mann, Hausdorff means and the Gibbs phenomenon, Doctoral Dissertation, Yeshiva University, 1964.

7. D. J. Newman, The Gibbs phenomenon for Hausdorff means, Pacific J. Math. 12 
(1962), 367-370.

8. O. Szász, Gibbs phenomenon for Hausdorff means, Trans. Amer. Math. Soc. 69 (1950), 440-456.

9. E. C. Titchmarsh, The theory of functions, 2nd ed., Oxford, 1939.

10. D. V. Widder, The Laplace traneform, Princeton, 1941.

City College and Yeshiva University 



\title{
PACIFIC JOURNAL OF MATHEMATICS
}

\author{
EDITORS
}

\author{
H. Samelson \\ Stanford University \\ Stanford, California \\ R. M. Blumenthal \\ University of Washington \\ Seattle, Washington 98105
}

\author{
J. DugundjI \\ University of Southern California \\ Los Angeles, California 90007 \\ Richard Arens \\ University of California \\ Los Angeles, California 90024
}

\section{ASSOCIATE EDITORS}
E. F. BECKENBACH
B. H. NEUMaNN
F. WOLF
K. YosIDA

\section{SUPPORTING INSTITUTIONS}

\author{
UNIVERSITY OF BRITISH COLUMBIA \\ CALIFORNIA INSTITUTE OF TECHNOLOGY \\ UNIVERSITY OF CALIFORNIA \\ MONTANA STATE UNIVERSITY \\ UNIVERSITY OF NEVADA \\ NEW MEXICO STATE UNIVERSITY \\ OREGON STATE UNIVERSITY \\ UNIVERSITY OF OREGON \\ OSAKA UNIVERSITY \\ UNIVERSITY OF SOUTHERN CALIFORNIA
}

\author{
STANFORD UNIVERSITY \\ UNIVERSITY OF TOKYO \\ UNIVERSITY OF UTAH \\ WASHINGTON STATE UNIVERSITY \\ UNIVERSITY OF WASHINGTON \\ AMERICAN MATHEMATICAL SOCIETY \\ CALIFORNIA RESEARCH CORPORATION \\ SPACE TECHNOLOGY LABORATORIES \\ NAVAL ORDNANCE TEST STATION
}

Mathematical papers intended for publication in the Pacific Journal of Mathematics should by typewritten (double spaced). The first paragraph or two must be capable of being used separately as a synopsis of the entire paper. It should not contain references to the bibliography. Manuscripts may be sent to any one of the four editors. All other communications to the editors should be addressed to the managing editor, Richard Arens, at the University of California, Los Angeles, California 90024.

50 reprints per author of each article are furnished free of charge; additional copies may be obtained at cost in multiples of 50 .

The Pacific Journal of Mathematics is published quarterly, in March, June, September, and December. Effective with Volume 13 the price per volume (4 numbers) is $\$ 18.00$; single issues, $\$ 5.00$. Special price for current issues to individual faculty members of supporting institutions and to individual members of the American Mathematical Society: $\$ 8.00$ per volume; single issues $\$ 2.50$. Back numbers are available.

Subscriptions, orders for back numbers, and changes of address should be sent to Pacific Journal of Mathematics, 103 Highland Boulevard, Berkeley 8, California.

Printed at Kokusai Bunken Insatsusha (International Academic Printing Co., Ltd.), No. 6, 2-chome, Fujimi-cho, Chiyoda-ku, Tokyo, Japan.

PUBLISHED BY PACIFIC JOURNAL OF MATHEMATICS, A NON-PROFIT CORPORATION

The Supporting Institutions listed above contribute to the cost of publication of this Journal, but they are not owners or publishers and have no responsibility for its content or policies. 


\section{Pacific Journal of Mathematics}

\section{Vol. 15, No. $2 \quad$ October, 1965}

Patrick Robert Ahern, On the generalized F. and M. Riesz theorem......... 373

A. A. Albert, On exceptional Jordan division algebras ................ 377

J. A. Anderson and G. H. Fullerton, On a class of Cauchy exponential

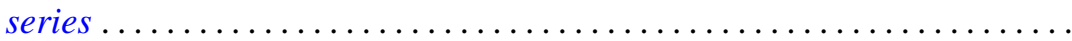

Allan Clark, Hopf algebras over Dedekind domains and torsion in

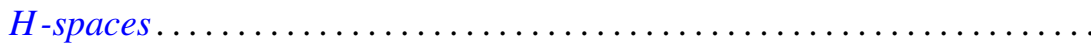

John Dauns and D. V. Widder, Convolution transforms whose inversion functions have complex roots .............................

Ronald George Douglas, Contractive projections on an $\mathrm{L}_{1}$ space ..........

Robert E. Edwards, Changing signs of Fourier coefficients ...............

Ramesh Anand Gangolli, Sample functions of certain differential processes on symmetric spaces .....................................

Robert William Gilmer, Jr., Some containment relations between classes of

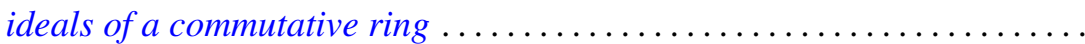

Basil Gordon, A generalization of the coset decomposition of a finite

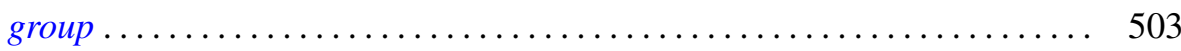

Teruo Ikebe, On the phase-shift formula for the scattering operator....... 511

Makoto Ishida, On algebraic homogeneous spaces ................ 525

Donald William Kahn, Maps which induce the zero map on homotopy ........ 537

Frank James Kosier, Certain algebras of degree one ................. 541

Betty Kvarda, An inequality for the number of elements in a sum of two sets of lattice points.................................

Jonah Mann and Donald J. Newman, The generalized Gibbs phenomenon for regular Hausdorff means. .

Charles Alan McCarthy, The nilpotent part of a spectral operator. II . ...

Donald Steven Passman, Isomorphic groups and group rings ...

R. N. Pederson, Laplace's method for two parameters .....

Tom Stephen Pitcher, A more general property than domination for sets of probability measures .............................

Arthur Argyle Sagle, Remarks on simple extended Lie algebras. .

Arthur Argyle Sagle, On simple extended Lie algebras over fields of

characteristic zero.

Tôru Saitô, Proper ordered inverse semigroups ...........

Oved Shisha, Monotone approximation

Indranand Sinha, Reduction of sets of matrices to a triangular form

Raymond Earl Smithson, Some general properties of multi-valued

functions .................................

John Stuelpnagel, Euclidean fiberings of solvmanifolds .... 